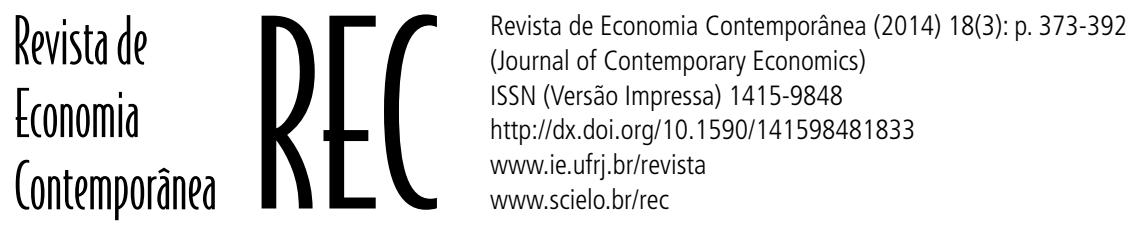

\title{
A ECONOMIA INSTITUCIONAL E AS TRÊS DIMENSÕES DAS INSTITUIÇÕES
}

\author{
Carolina Miranda Cavalcante ${ }^{a}$ \\ ${ }^{a}$ Faculdade Nacional de Direito da Universidade Federal do Rio de Janeiro (FND/UFRJ).
}

Artigo recebido em 23/10/2014 e aceito em 26/01/2015.

\begin{abstract}
RESUMO: Esse artigo tem por objetivo discutir os diferentes sentidos conferidos ao termo "instituição". Apesar das definições de instituição terem encontrado certo consenso em torno da ideia de regras de comportamento, muito amiúde não é claro o objeto ao qual se referem os autores quando falam em instituições. Nesse sentido, destacamos três dimensões institucionais, ou sentidos conferidos ao termo instituição, que são encontrados na literatura especializada. São elas: (i) instituições como regras do jogo; (ii) instituições como modelos mentais; e (iii) instituições como organizações. Deste modo, uma distinção entre a velha e a nova economia institucional está cada vez mais difícil de ser realizada, justamente por conta da confusão dessas dimensões institucionais num único termo. Por fim, veremos que institucionalistas contemporâneos como Hodgson e Chang transitam de modo bastante fluido entre essas dimensões institucionais.
\end{abstract}

PALAVRAS-CHAVE: Instituições; regras do jogo; organizações; modelos mentais; dimensões institucionais.

CLASSIFICAÇÃO JEL: B520.

Correspondência para Carolina Miranda Cavalcante.

a E-mail: cmcavalcante@gmail.com. 


\section{INSTITUTIONAL ECONOMICS AND THE THREE DIMENSIONS OF INSTITUTIONS}

ABSTRACT: This article aims to discuss the different meanings given to the term "institution". Although the definitions of institution have found some consensus around the idea of rules of behavior, too often it is not clear the object to which the authors refer when they speak of institutions. Thus, we highlight three institutional dimensions, or directions given to the term institution, which are found in the literature: (i) institutions as rules of the game; (ii) institutions as mental models; and (iii) institutions as organizations. Thus, a distinction between the old and the new Institutional Economics is increasingly difficult to draw, precisely because of the confusion of these institutional dimensions in a single term. Finally, we see the usage of that term by contemporary institutionalists as Hodgson and Chang moves quite fluidly between these institutional dimensions.

KEYWORDS: Institutions; game rules; organizations; mental models; institutional dimensions.

\section{INTRODUÇÃO}

Diariamente ouvimos falar em instituições - instituições sociais, instituições financeiras, instituições de ensino, instituição familiar e umas tantas outras instituições -, mas do que exatamente está se falando quando se usa o termo "instituição" de modo tão genérico? Poderíamos pensar que certa confusão quanto ao sentido de um termo não é incomum no uso cotidiano, afinal, as pessoas não precisam se ocupar com formalidades científicas em seu trato pessoal. Contudo, o fato curioso é que essa confusão quanto ao sentido do termo "instituição" também está presente no âmbito dos debates acadêmicos em economia institucional. Naturalmente, ao contrário do senso comum, os institucionalistas preocuparam-se em definir o que é uma instituição, de modo que o dissenso explicita diversidade, mas não falta de uma definição, ou de muitas definições, para o termo "instituição".

O objetivo desse artigo é justamente explicitar esse dissenso no âmbito da economia institucional, buscando tornar claros os sentidos nos quais se usa o termo “instituição" na literatura especializada. Nesse sentido, convidamos o leitor a uma breve imersão nos textos de alguns institucionalistas, para que possamos traçar as diferenças e também as semelhanças conceituais referentes à definição do termo "instituição".

Esse artigo encontra-se estruturado em três itens, além dessa introdução e de uma conclusão ao final do trabalho. No primeiro item faremos uma breve exposição de alguns autores da velha economia institucional (VEI) - Veblen, Commons e Mitchell - e da nova economia institucional (NEI) - North, Coase e Williamson. No segundo item, veremos que institucionalistas contemporâneos como Hodgson e Chang transitam de modo fluido entre os conceitos de instituição enquanto regras do jogo, modelos mentais e organizações. No terceiro item discutiremos em que medida a perspectiva dos referidos autores aproxima-se de uma ou mais dimensões institucionais, a saber, (i) instituições como regras do jogo; (ii) instituições como modelos mentais; e (iii) instituições como organizações.

\section{OS INSTITUCIONALISTAS: VELHOS E NOVOS}

A economia institucional conquistou seu lugar, enquanto programa de pesquisa, no pensamento econômico no final do século XIX com os escritos seminais de Thorstein Veblen, porquanto elementos institucionais possam ser identificados nos escritos de autores como Adam Smith, Karl Marx e Alfred Marshall (Hodgson, 1999). Contudo, nosso ponto de partida será a velha economia institucional de Veblen, 
Commons e Mitchell, que mais tarde seria oposta à nova economia institucional de North, Coase e Williamson ${ }^{1}$.

A velha economia institucional tem início com o artigo seminal de Thorstein Veblen, Why is Economics not an Evolutionary Science, publicado em 1898, no qual o autor defende uma ciência econômica que reconheça o processo evolutivo das instituições, tendo como principais seguidores de seu pensamento Wesley Mitchell e John Commons. Apesar dos primeiros escritos do incipiente programa de pesquisa institucionalista terem surgido no final do século XIX, apenas em 1919 foi sugerido o termo "economia institucional", cunhado por Walton Hamilton e que daria nome a essa nova disciplina no âmbito da Economia ${ }^{2}$. Já a demarcação entre a VEI e a NEI teria que esperar mais algumas décadas, até que Oliver Williamson se autodenominasse novo institucionalista ao lado de Douglass North e Ronald Coase, deixando clara a descontinuidade com o que chamou de velho institucionalismo (Coase, 1998, p. 72).

Veblen (1961 [1898]) tinha como alvo de sua crítica os supostos da ortodoxia econômica de sua época, identificada com o pensamento de John Bates Clark (Rutherford, 2001, p. 18). O velho institucionalismo argumentava a favor de uma ciência empírica, diferente das formulações teóricas ortodoxas, baseadas em hipóteses irrealistas, fundamentadas em suposições psicológico-comportamentais que possuíam pouco contato com o funcionamento real da economia (Rutherford, 2001, p. 177). No lugar dessas formulações teóricas excessivamente abstratas, Veblen sugeriu uma reformulação da teoria econômica que se sustentasse sobre os pilares de uma ciência evolucionária, que seria uma "teoria do processo, de uma seqüência que se desdobra" (Veblen, 1961, p. 58).

A ciência evolucionária sugerida por Veblen opunha-se à teoria ortodoxa, propondo uma explicação envolvendo cadeias de causa e efeito, em lugar de uma teorização ortodoxa, não evolucionária, que explicaria os fenômenos econômicos em termos de algum propósito. Essa teleologia implicada na ciência não evolucionária foi denominada por Veblen como animismo. Esse modo de entender o mundo econômico levaria a outro problema da ciência não evolucionária, a taxonomia, que consistiria

1 Naturalmente, existem mais autores associados ao velho institucionalismo, como Clarence Ayres, por exemplo, mas precisamos limitar um pouco os autores representativos de cada programa de pesquisa para fins de apresentação. Para mais sobre o velho institucionalismo ver Rutherford (1994), Hodgson (1994) e Ferrari e Conceição (2001). Théret (2003) aponta ainda três vertentes no âmbito da nova economia institucional, uma referente aos custos de transação - Coase e Williamson -, outra concernente à temática da história uma referente aos custos de transação - Coase e Williamson -, outra concernente à temática da história
econômica e da mudança institucional - North e R. C. O. Matthews - e, por fim, uma envolvida no estudo do econômica e da mudança institucional - North e R. C. O. Matthews - e, por fim, uma envolvida no estudo do equilibrio num contexto de interações estratégicas - Thomas Schelling, Andrew Schotter e Martin Shubik. Para um trabalho bastante completo sobre o novo institucionalismo ver Furubotn e Richter (2005).

2 Ver Hodgson (2000) e Rutherford (2001). Ver também Bueno (2004), Conceição (2002a; 2002b) e Medei$\operatorname{ros}(2001)$. numa construção teórica baseada na dedução de fenômenos econômicos a partir de postulados gerais como "homem econômico" e "competição perfeita". Ligado a esses dois problemas está o que Veblen denominou como hedonismo, uma forma peculiar da ciência evolucionária entender o homem, o agente econômico, que o definiria como um sujeito capaz de realizar todos os cálculos necessários à maximização do prazer e/ou à minimização da dor, em termos veblenianos um "calculador instantâneo de dor e prazer" (Veblen, 1961 [1898], p. 73).

Como contraponto à psicologia hedonista, Veblen sugeriu não apenas a ideia de um processo evolutivo, mas também uma teoria dos instintos. Segundo Veblen, os homens seriam movidos por três instintos: (i) instinto de artesanato (workmanship), que seria a tendência à implementação de incrementos tecnológicos; (ii) instinto familiar (parental bent), que inclinaria o sujeito a buscar a melhora do bem-estar da família e da sociedade; (iii) instinto de curiosidade (idle curiosity), que levaria o sujeito a produzir explicações coerentes do mundo (Rutherford, 1984, p. 332). Contudo, mais importante que os instintos seriam as instituições que, segundo Veblen, ganhariam autonomia em relação aos instintos, mostrando-se até capazes de moldar esses instintos.

Em seu livro de 1899, The Theory of the Leisure Class, Veblen aplica sua concepção de instituição à evolução da vida social a partir de um processo contínuo de mudança nos hábitos mentais dos sujeitos. Assim chegamos à compreensão vebleniana de instituições como hábitos mentais, que seriam "métodos habituais de dar continuação ao modo de vida da comunidade em contato com o ambiente material no qual ela vive" (Veblen, 1988 [1899], p. 89). Hábitos mentais são, segundo Veblen (1961 [1898]), formas de ser e de fazer as coisas que se cristalizam em instituições, mantidas ou modificadas ao longo do tempo pela ação reprodutiva ou transformadora dos sujeitos. Destarte, as instituições comporiam o tecido social alimentando-se das ações e decisões dos sujeitos e ao mesmo tempo as modificando ao longo do tempo.

Seguindo a linha vebleniana, Mitchell (1910a) também entendia instituições como hábitos mentais, como "hábitos de pensamento predominantes que ganharam aceitação geral como normas orientadoras da conduta” (Mitchell, 1910b, p. 203). Mitchell descarta a fundamentação da ortodoxia de sua época em supostos acerca de uma natureza humana, sugerindo novas bases psicológicas para a ciência econômica, ratificando a definição de instituições como hábitos mentais, como "entidades psicológicas - hábitos mentais e de ação predominantes dentre as comunidades sob observação" (Mitchell, 1910a, p. 112).

Apesar de ter adotado as ideias veblenianas, como a definição de instituições como hábitos mentais, a distinção entre a fase pecuniária e a fase tecnológica da vida econômica como responsáveis pelos distintos hábitos mentais, a ideia de um processo evolutivo da sociedade, bem como a crítica às teorias abstratas da economia ortodoxa de sua 
época, Mitchell não concordou com as concepções mais radicais de Veblen, como a rejeição completa da ciência econômica considerada ortodoxa ${ }^{3}$. Deste modo, apesar de discípulo de Veblen, Mitchell aproximou-se da economia ortodoxa, dela aproveitando o que julgou útil à construção de seu corpo teórico complexo.

Assim como Mitchell, Commons é considerado um discípulo de Veblen, tendo também se colocado como um crítico menos radical da economia ortodoxa de sua época. Ademais, ao basear seu argumento nos conceitos de escassez e de transação, Commons acabou por se tornar o mais importante institucionalista americano sob o ponto de vista dos novos institucionalistas (Furubotn e Richter, 2005, p. 41). Segundo Commons (1931), a economia institucional remontaria à ideia de David Hume de que a escassez de recursos levaria ao conflito de interesses. De acordo com Veblen, e com Mitchell, o conflito emergiria de hábitos mentais distintos, não da escassez de recursos, como afirmara Commons. A noção de instituição de Commons surge do argumento de que a escassez de recursos seria resolvida unicamente com base na força física, caso não existissem restrições à ação individual. Essas restrições seriam postas pela ação coletiva no exercício do controle coletivo, que se tornaria operante através dos mecanismos institucionais. $\mathrm{O}$ autor, então, define uma instituição:

Se nós queremos encontrar uma circunstância universal, comum a todo comportamento conhecido como institucional, devemos definir uma instituição como a ação coletiva em controle, liberação e expansão da ação individual. (Commons, 1931, s. p.)

As instituições são, para Commons, mecanismos através dos quais o controle coletivo é exercido, devendo desempenhar ainda a função de mecanismo de resolução de conflitos com base em regras e punições ao seu descumprimento. Esse controle coletivo, exercido através das instituições, pode advir de costumes desorganizados (unorganized customs) ou da ação organizada (organized action), que compreende o Estado, a família, a Igreja, as corporações, os sindicatos etc. (Commons, 1931). As instituições componentes da ação organizada possuem um conjunto de regras de funcionamento (working rules), que definem "o que os indivíduos podem, não podem, devem, não devem, poderiam ou não poderiam fazer” (Commons, 1931, s. p.).

No esquema conceitual de Commons, as instituições possuiriam o papel instrumental de resolver conflitos sem recurso à força física, regulando as relações sociais conflito, dependência e ordem - que, segundo o autor, estariam implícitas nas transações. Uma transação é entendida, pelo autor, como "a alienação e a aquisição, entre indivíduos, dos direitos de propriedade e liberdade criados pela sociedade" (Com-

Ver Rutherford (1998, 2001), Backhouse (1985), Mitchell (1914) mons, 1931, s. p.). Nesse sentido, Commons acaba por identificar a transação com a relação de propriedade, entendendo a transação como uma espécie de "acordo", coletivo e inicial entre os indivíduos, que possibilitaria um sistema econômico capaz de produzir, distribuir e trocar mercadorias. Por conta disso Commons considerou a transação como a unidade básica de análise. Desta forma, num sistema no qual a escassez de recursos leva à resolução de conflitos através da força física, esse acordo coletivo inicial entre os indivíduos somente pode ocorrer de forma minimamente pacífica com recurso à ação coletiva, cristalizada em instituições.

O novo institucionalismo pode ser visto como uma reação da economia neoclássica à crítica quanto à falta de empiria e de um conceito de instituição no âmbito da teoria econômica ortodoxa, uma vez que North $(1981,1990)$, um dos novos institucionalistas mais referidos, deixa claro que seu objetivo é ampliar o conjunto de questões consideradas pelo programa de pesquisa neoclássico, não substituí-lo. O mesmo caminho é seguido por Coase e por Williamson.

Através da proposição do conceito de custos de transação, Coase teria lançado as bases da nova economia institucional, embora North e Williamson tenham utilizado tal conceito de forma diversa (North, 1992, p. 6). Os custos de transação podem ser definidos como "o custo de usar o mecanismo de preços" ou "o custo de se levar uma transação adiante através de uma troca no mercado” (Coase, 1998, p. 6). Nesse sentido, os custos de transação são todos aqueles envolvidos numa transação econômica, como a pesquisa de preços, os contratos, bem como o próprio conhecimento do mercado. A ideia de que toda transação possui um custo surgiu no artigo de 1937 de Coase - The Nature of the Firm -, no qual o autor investiga o porquê da existência de firmas em economias reguladas unicamente pelo mercado, criticando a pouca atenção dispensada à firma pela teoria econômica tradicional. Mesmo a utilização do mercado enquanto mecanismo de alocação de recursos possuiria, segundo Coase (1990), seus custos de operação.

Deste modo, os custos de transação estariam por toda parte, cabendo aos indivíduos sua minimização através da escolha do mecanismo de alocação de recursos - firmas, mercado e Estado - no qual estivesse implicado o menor custo de transação (Coase, 1937, 1960). Coase identifica esses mecanismos de alocação de recursos com as instituições que, segundo o autor, seriam justamente a firma, o mercado e o Estado. Sendo assim, o papel de uma instituição no mundo econômico de Coase $(1937,1995)$ é o de redutor dos custos de transação existentes.

Assim como Coase, Williamson (1985, p. 15) compreende instituições como firmas, mercados e relações contratuais. Williamson aceita a proposição de Commons da transação como unidade básica de análise, adotando ainda a ideia de custos de transação de Coase no âmbito de uma teoria da firma, bem como os conceitos de racionali- 
dade limitada, desenvolvido por Simon (s. d.; 1979), e de oportunismo, entendido como "uma profunda condição de busca pelo autointeresse que inclui a malícia" (Williamson, 1993b, p. 92).

O suposto comportamental de racionalidade limitada não implica que os indivíduos sejam irracionais, apenas sugere que estes possuem limitações computacionais e informações incompletas para realizar suas escolhas. Racionalidade limitada ${ }^{4}$ seria $o$ termo "usado para designar escolha racional que leva em consideração as limitações cognitivas do agente que toma decisões - limitações tanto do conhecimento quanto da capacidade computacional" (Simon, s. d., p. 15). Destarte, num mundo econômico no qual os indivíduos possuem uma capacidade computacional limitada não podem existir resultados ótimos, uma vez que esses indivíduos não estão aptos a realizar todos os cálculos necessários à escolha ótima.

Ao não capturar o sistema econômico em sua completude, suas decisões necessitam de apoios, de regras existentes fora da mente dos indivíduos e ao menos relativamente independente deles, ou seja, o processo de decisão de indivíduos limitados cognitivamente apóia-se em instituições. No mundo econômico de Williamson, os indivíduos são oportunistas e limitados cognitivamente, necessitando de instituições como as firmas, os mercados e as relações contratuais como formas de reprimir o comportamento oportunista e de apoiar as escolhas, servindo de complemento computacional.

North também adota as ideias de custos de transação e de racionalidade limitada, mas no âmbito das modificações na matriz institucional e do Estado, numa abordagem mais voltada à temática do desenvolvimento econômico. Ademais, a definição de instituição mais referida e aceita talvez seja a de North, que entende instituições como as regras do jogo numa sociedade. $\mathrm{O}$ autor assim define as instituições:

Instituições são restrições humanamente concebidas que estruturam as interações políticas, econômicas e sociais. Elas consistem tanto em restrições informais (sanções, tabus, costumes, tradições, e códigos de conduta), quanto em restrições formais (constituições, leis, direitos de propriedade). (North, 1991, p. 97)

Deste modo, North identifica instituições com regras, formais e informais, de comportamento. Essas regras são criadas pelos indivíduos para servir de restrição à sua própria ação, permitindo a interação social. Nessa perspectiva, os indivíduos respeitam as regras porque existem sanções implicadas em seu descumprimento. Essa é uma visão que descreve o agente econômico como um indivíduo oportunista, que so-

4 Rizzello (1997, p. 43) aponta que o termo racionalidade limitada teria sido utilizado pela primeira vez por Simon em seu trabalho Administrative Behaviour, de 1947. Ver também Dequech (2001). mente pode ter seu agir puramente autointeressado freado pelas sanções postas em sua maior parte pelo Estado. Segundo o autor, o Estado pode impor sanções ao descumprimento das regras porque "é uma organização com vantagem comparativa em violência" (North, 1981, p. 21). Importante notar que North não define o Estado como uma instituição, mas como uma organização, definindo instituição como um conjunto de regras.

Contudo, o autor reconhece que os indivíduos podem agir de forma não oportunista, ou seja, podem deixar de tirar proveito numa situação na qual sua punição seria improvável. Isso explicaria o porquê de um indivíduo devolver ao dono uma maleta repleta de dinheiro quando poderia, sem risco de punição, ficar com todo o dinheiro. Esse comportamento que respeita as regras, de propriedade, nesse caso, mesmo na ausência de uma provável punição é explicado pela ideologia, que North assim define:

Por ideologia entendo as percepções subjetivas (modelos, teorias) que todas as pessoas possuem para explicar o mundo à sua volta. Seja no nível micro dos relacionamentos individuais seja no nível macro das ideologias organizadas provedoras de explicações integradas do passado e do presente, como o comunismo ou as religiões, as teorias que os indivíduos constroem são coloridas por visões normativas de como o mundo deve ser organizado. (North, 1990, p. 23)

A ideologia seria, para North, os modelos mentais que construímos acerca da realidade na qual vivemos, ou seja, é a visão que os indivíduos têm do mundo. Nesse sentido, os indivíduos internalizam algumas regras do jogo, as respeitando não porque podem ser punidos, mas simplesmente porque acham adequado respeitá-las. Aqui a adequação refere-se às regras internalizadas pelos indivíduos e que eles acreditam que deveriam seguir por princípio, em outras palavras, as regras internalizadas pelos agentes econômicos são regras impostas e policiadas pelo próprio indivíduo.

North adota ainda a ideia de racionalidade limitada, entendendo as instituições como complementos cognitivos para indivíduos incapazes de processar todas as informações necessárias à escolha ótima. Destarte, as regras postas pelo sistema social e as regras internalizadas servem de apoio para a tomada de decisão do indivíduo, fornecendo a noção do que deve e o que não deve ser feito, do certo e do errado, permitindo ao agente cognitivamente limitado fazer escolhas, tomar decisões e agir no mundo social. Em livro mais recente, North caminha um pouco mais em direção de uma abordagem mais psicológica das instituições:

O foco da nossa atenção, portanto, deve ser o aprendizado humano - no que é aprendido e como este é compartilhado entre os membros da sociedade e no processo incremental através do qual as crenças e preferências mudam, e no modo pelo qual elas moldam a performance das economias ao longo do tempo. (North, 2005, p. viii) 
Aqui o autor chama a atenção para o processo de aprendizado e como ele pode contribuir no desempenho e no desenvolvimento das economias ao longo do tempo. A mudança institucional continua sendo importante, mas importa agora saber como, e em qual velocidade, os indivíduos processam essa mudança. North está tratando aqui da maleabilidade dos modelos mentais, ou das regras internalizadas, dos agentes econômicos. Quanto maior a capacidade dos indivíduos de uma economia em absorver modelos mentais positivos ao desenvolvimento, maior o potencial dessa economia para o desenvolvimento.

\section{INSTITUCIONALISTAS CONTEMPORÂNEOS}

O velho e o novo institucionalismo são novamente debatidos por institucionalistas contemporâneos como Geoffrey Hodgson e Ha-Joon Chang, que terão suas ideias apresentadas nesse item. Uma característica do institucionalismo contemporâneo é a interdisciplinaridade e o aproveitamento de conceitos e ideias tanto do velho quanto do novo institucionalismo, dando pouca ênfase a uma mera oposição entre essas duas vertentes do pensamento institucionalista.

Embora diversos autores possam ser considerados institucionalistas contemporâneos, nesse artigo, elegemos para exposição apenas as contribuições de Hodgson e de Chang. Vamos iniciar com dois artigos de Hodgson, um de 2001, intitulado A evolução das instituições: uma agenda para pesquisa teórica futura, e outro, de 2006, com o interrogativo título What are institutions?. É importante notar que esses dois artigos não esgotam as concepções institucionalistas de Hodgson, mas nos fornecem elementos para posicioná-lo nos debates no âmbito da Economia Institucional.

Hodgson é um autor que busca o diálogo com o institucionalismo de North sem, contudo, deixar de lado sua raiz vebleniana, o que nos permitiria denominá-lo como um pós-vebleniano ${ }^{5}$. Hodgson (2001) assinala uma distinção metodológica entre a VEI e a NEI quanto ao papel dos sujeitos no que concerne às instituições. Enquanto os novos institucionalistas adotariam um "modelo de baixo para cima", no qual as instituições emergiriam de um estado de natureza povoado de indivíduos dotados de preferências exógenas, os velhos institucionalistas estariam comprometidos com um "modelo de causação reconstitutiva de cima para baixo", no qual a emergência de uma instituição sempre pressuporia a preexistência de outra instituição (Hodgson, 2000, p. 12).

${ }^{5}$ Cavalcante (2007, p. 46)
Contra a ideia de um estado de natureza livre de instituições, Hodgson sugere um indissolúvel círculo de determinação mútua entre indivíduos e instituições, ainda que sejam ontologicamente distintos. O autor aponta que a amplitude de vida de indivíduos e instituições é diferente, assim como seus mecanismos de reprodução (Hodgson, 2001, p. 104). Assim sendo, Hodgson (2001) define instituições como regras, restrições, práticas e ideias que podem moldar as preferências dos indivíduos. Nesse ponto, o autor busca explicitamente conciliar a visão de instituição como regras do jogo de North com a concepção de instituição como modelos mentais de Veblen. Nas palavras do autor:

Instituições são os tipos de estruturas que mais importam no domínio social: elas compõem o material da vida social. (...) nós devemos definir instituições como sistemas de regras sociais estabelecidas e prevalecentes que estruturam as interações sociais. Linguagem, dinheiro, lei, sistema de pesos e medidas, maneiras à mesa, firmas (e outras organizações) são, portanto, todos instituições. (Hodgson, 2006, p. 2)

No entanto, as instituições não apenas estruturam as interações sociais, elas são, também, reforçadas e mantidas pelo comportamento individual através do hábito Hodgson toma o conceito de hábito do pensamento de Veblen e da filosofia pragmatista, em que os hábitos seriam formados a partir da repetição da ação ou do pensamento. Ainda segundo o autor, hábito não é sinônimo de comportamento, mas sim propensão a um determinado comportamento condicionado a uma dada situação (Hodgson, 2001, p. 107). Além disso, "hábitos são mais que um meio de economizar no processo de tomada de decisão para os indivíduos; estes são um meio através do qual as convenções sociais e as instituições são formadas e preservadas" (Hodgson e Knudsen, 2004, p. 36).

Uma vez que hábitos se estabelecem, tornam-se uma base potencial para novas intenções e crenças. Como resultado, hábitos compartilhados são material constitutivo de instituições, dotando-as de acentuada durabilidade, de poder e de autoridade normativa. (Hodgson, 2001, p. 108)

Numa clara referência ao pensamento de Veblen, Hodgson sustenta que os hábitos compartilhados seriam capazes de moldar e constituir as instituições, que se converteriam em regras sociais responsáveis pela estruturação das interações entre as pessoas. Essa é a essência do "modelo de causação reconstitutiva de cima para baixo" sugerido por Hodgson, no qual as instituições têm o papel de estruturar as interações individuais, ao mesmo tempo em que permanecem permeáveis às ações dos indivíduos.

Chang segue um caminho semelhante ao de Hodgson ao sugerir essa permeabilidade mútua entre instituições e indivíduos, sem, contudo, entrar em detalhes metodológicos. A proposta de Chang é a de uma economia política institucional, que o autor 
opõe ao que ele denominou como paradigma neoliberal, resultante da união entre o instrumental teórico neoclássico e a filosofia política e moral da escola austríaca (Chang, 2002, p. 540). Em especial, o autor questiona a definição de North de instituição como regras do jogo que restringem o comportamento humano. Segundo Chang, essa compreensão de instituições como restrições limitaria seu papel na sociedade, uma vez que as instituições possuiriam um papel mais amplo de restringir, constituir e possibilitar a ação humana (Chang e Evans, 2005, p. 5). Dentre as instituições presentes no ambiente econômico, o autor menciona três instituições importantes, a saber: $\mathrm{o}$ mercado, as firmas e o Estado.

O sistema capitalista é composto de uma cadeia de instituições, incluindo os mercados como instituições de troca, as firmas como instituições de produção, e o Estado como criador e regulador das instituições que governam suas conexões (enquanto instituição política), assim como outras instituições informais como as convenções sociais. (Chang, 2002, p. 546)

Importante notar, nessa passagem, que Chang menciona justamente as três instituições consideradas por Coase, um novo institucionalista, como centrais ao funcionamento do sistema econômico. Naturalmente, Chang não entende essas instituições como meros mecanismos de alocação de recursos, conforme fizera Coase. Todavia, fica evidente que Chang considera que uma instituição pode ser tanto a regra, que restringe, constitui e possibilita as ações dos indivíduos, quanto um conjunto de regras componente de uma organização - firmas, Estado e mercado.

Deste modo, o autor sustenta que as instituições devem ser entendidas como "mecanismos que possibilitam o alcance de finalidades que requerem coordenação supraindividual e, ainda mais importante, que são constitutivas dos interesses e visões de mundo dos atores econômicos" (Chang e Evans, 2005, p. 2). Ademais, as instituições são persistentes e estáveis, o que não implica sua imutabilidade, uma vez que "são os homens que modificam as instituições, mas não no contexto institucional de sua própria escolha" (Chang, 2005, p. 18).

(...) nossa abordagem difere daquela da NEI [nova economia institucional] ao postular uma causação de mão-dupla entre as motivações individuais e as instituições sociais, em lugar de uma causação de mão-única dos indivíduos para as instituições, embora acreditemos que em última análise as instituições sejam pelo menos 'temporariamente' anteriores aos indivíduos. (Chang e Evans, 2005, p. 5)

Como podemos observar, a principal reação de Chang aos novos institucionalistas remete à colocação de instituições e indivíduos em campos opostos e impermeáveis, afirmando ainda que o sistema capitalista não deveria ser visto como um mero agru- pamento de instituições que os indivíduos podem construir e descartar de acordo com seus objetivos de maximização. Contra essa visão, Chang afirma que uma instituição é um complexo de regras formais e informais, mantidas e/ou transformadas por agentes intencionais, em que firmas, Estado e mercado se inter-relacionam, moldando o sistema capitalista.

Por conseguinte, assim como Hodgson, Chang também identifica um "modelo de baixo para cima" no pensamento novo institucionalista. Os autores não discordam que instituições possuem um componente restritivo no que concerne às regras, mas chamam a atenção para o fato de que as instituições moldam ao mesmo tempo em que são moldadas pela ação individual. Dito de outro modo, a ação individual não pode ocorrer num vácuo institucional, da mesma maneira que as instituições não podem existir na ausência da ação individual. Existe, portanto, uma mútua dependência ontológica entre instituições e ação humana, em que uma não pode existir sem a outra.

Deste modo, Hodgson e Chang reagem a uma definição estrita de instituição como regra restritiva ao comportamento individual, trazendo o pensamento vebleniano para o debate na tentativa de construir uma visão de instituição mais conectada à ação humana. Isso fica claro na ideia de Chang de que as instituições seriam mecanismos capazes de restringir, constituir e possibilitar a ação humana, ou seja, as instituições seriam capazes de moldar a visão de mundo dos indivíduos. Essa ideia de instituição é compatível com a proposição de Hodgson de um "modelo reconstitutivo de cima para baixo", em que o hábito cumpre um importante papel de reforçar padrões de comportamento cristalizados em instituições.

\section{DIMENSÕES INSTITUCIONAIS}

Como foi possível observar nos itens anteriores, principalmente no item referente aos autores da VEI e da NEI, o termo instituição é tratado e definido de formas distintas. Contudo, em vez de buscar demarcar as fronteiras da VEI e da NEI, veremos que é possível identificar três dimensões institucionais, ou três formas de se entender e definir uma instituição: (i) instituições como regras do jogo; (ii) instituições como modelos mentais; e (iii) instituições como organizações ${ }^{6}$.

Quando falamos em instituições como regras do jogo, podemos mencionar as ideias de North, que fornece a definição de instituição mais citada atualmente. Na concepção de North, as instituições seriam as regras do jogo na sociedade, represen-

\footnotetext{
6 Ver Cavalcante (2010).
} 
tando para os indivíduos um conjunto de restrições à sua ação. Essas restrições podem ser formais, como as leis e as constituições, ou podem ser informais, postas pelos costumes e tradições de uma sociedade. O autor afirma ainda que pode ser feita uma analogia do conceito de instituições com as regras formais e informais de um esporte coletivo como o futebol, em que existem as regras por todos conhecidas, as regras formais, bem como aquelas que dependem das tradições e do bom senso dos participantes do jogo, as regras informais. As instituições, nessa perspectiva, dizem aos indivíduos o que eles podem ou não podem fazer, ou seja, fornece os limites para a ação humana. Essas restrições são postas pela própria sociedade ou por organizações, como o Estado. North trata o Estado como uma organização, que pode ser entendida como uma entidade capaz de criar, destruir e manter as regras do jogo, em que essa organização mesma possui suas regras constituintes.

A ideia de organizações como um conjunto de regras que definem o que os indivíduos podem ou não podem fazer é compatível com a compreensão de Commons acerca de instituições como organizações. Vimos que o autor entende as instituições como os mecanismos através dos quais o controle coletivo é exercido, servindo ainda como mecanismos de resolução de conflitos. Ou seja, quando deixados à sua própria sorte, sem regras, sem instituições, os indivíduos tenderiam a resolver seus conflitos com base na força física. Esse controle coletivo pode ser exercido de forma não organizada, o que seria análogo às regras informais em North, ou de forma organizada, representada na figura do Estado, da família, da Igreja, dos sindicatos, das corporações, dentre outras organizações. Deste modo, Commons entende instituição como um conjunto de regras advindas de alguma forma de controle coletivo, seja ele proveniente de costumes não organizados, seja ele originado da ação organizada, que se apresenta sob a forma de organizações como o Estado.

Enquanto North coloca as instituições enquanto regras do jogo (formais e informais) de um lado e organizações como um conjunto de regras do outro (Estado), essa demarcação não é tão evidente no pensamento de Commons. Contudo, podemos inferir a partir da definição de instituição fornecida por Commons que o autor entende uma instituição como um conjunto de regras que regula e fornece limites ao comportamento humano. Outro autor que não deixa explícita essa demarcação entre instituição e organização é Coase, que centra sua análise no tratamento dos custos de transação. Segundo o autor, firmas, Estado e mercado seriam mecanismos de alocação de recursos alternativos, em que os indivíduos escolheriam um dos três de acordo com os custos de transação envolvidos em cada um deles. Naturalmente, os indivíduos racionais escolheriam o mecanismo de alocação com menores custos de transação. Destarte, podemos entender esses mecanismos de alocação como regras de alocação, que, enquanto regras, podem ser entendidas como instituições. No pensamento de Coase, as instituições são vistas, assim como em Commons, como as regras que emanam de organizações como o Estado e as firmas, mas também podem ser entendidas como as próprias organizações.

Williamson, assim como Coase, identifica instituições com organizações como firmas, mercados e relações contratuais. Ao adotar o suposto de racionalidade limitada e de oportunismo como constituintes da modalidade de ação dos indivíduos, as instituições corporificadas em organizações tornam-se necessárias como complementos cognitivos para os indivíduos. Essa ideia de instituição como complemento cognitivo à racionalidade limitada dos indivíduos também aparece na argumentação de North, o que permite ao autor se colocar próximo a Veblen no que concerne à definição de instituição como modelos mentais ${ }^{7}$.

A ideia de racionalidade limitada, originalmente desenvolvida por Simon, permite a North fornecer os fundamentos para a ideia de instituição como regras complementares, existentes fora da mente do indivíduo. Se existem regras fora da mente dos indivíduos, existem também as regras internalizadas pelos indivíduos, ou modelos mentais. Uma das formas que essas regras assumem na mente do indivíduo consiste, segundo North, na ideologia, ou na visão que as pessoas possuem da realidade na qual vivem. Outra forma de internalização das regras do jogo remete ao aprendizado, principal motor do desenvolvimento econômico segundo North. De acordo com o autor, o tipo de aprendizado e a velocidade com que os indivíduos o adquirem ou o modificam reflete o grau de desenvolvimento econômico de uma sociedade. Deste modo, North entende instituições como regras fora da mente dos indivíduos, que são as regras formais e informais de uma sociedade, mas também admite que essas instituições possam ser internalizadas pelos indivíduos, constituindo seus modelos mentais ou a forma como entendem a realidade a sua volta.

Veblen define instituição como hábitos mentais, ou seja, como formas de ser e de fazer as coisas, que são mantidas ou modificadas ao longo do tempo pela ação das pessoas. Mitchell também entende instituição como hábitos mentais, ou hábitos de pensamento que adquiriram ao longo do tempo uma aceitação geral como normas que orientam a conduta das pessoas. Nessa perspectiva, as instituições são ao mesmo tempo formas de agir e de entender o mundo e os padrões, ou normas, que emergem de uma compreensão e de uma ação que obtiveram aceitação generalizada. Contudo, a ideia de instituição de Veblen parece permanecer num patamar mais abstrato que as regras do jogo de North, uma vez que os hábitos mentais de Veblen não se restringem à estrutura mental de um indivíduo específico, mas de um conjunto de pessoas pen-

Ver Dequech (2002). 
sando e fazendo a mesma coisa. Talvez essa divergência no pensamento dos autores seja originária das diferentes bases psicológicas adotadas pelos autores. Enquanto Veblen parte de uma ideia de sujeitos movidos por instintos, North entende os indivíduos como dotados de uma racionalidade limitada.

Já os institucionalistas contemporâneos transitam de modo mais fluido no âmbito dessas três formas de se entender e definir as instituições, o que reflete a tentativa, ao menos no caso de Hodgson, de conciliar a VEI e a NEI. Ao mesmo tempo em que Hodgson sugere uma definição de instituição como regras, restrições e práticas que podem moldar as preferências dos indivíduos, o autor também sustenta que esse conjunto de regras é reforçado e mantido pelo hábito. O hábito seria formado a partir da repetição da ação ou do pensamento, não sendo, contudo, sinônimo de comportamento, mas sim uma propensão a um determinado comportamento dada uma situação. Em outras palavras, Hodgson entende instituições como regras mantidas por hábitos, que nada mais são do que uma propensão à determinada ação ou comportamento. Assim sendo, podemos perceber no esquema conceitual de Hodgson elementos do pensamento de Veblen e de North.

Chang sugere uma economia política institucional como alternativa ao que ele denominou paradigma neoliberal, em que o principal alvo de sua crítica é o pensamento de North. Segundo Chang, as instituições deveriam ser entendidas como mecanismos que possibilitam, constituem e restringem a ação humana, podendo ainda ser identificadas com entidades como o Estado, as firmas e os mercados. Nesse sentido, Chang define instituições como regras do jogo, mas também as entende como organizações.

\section{CONCLUSÃO}

Talvez pelo caráter total da crítica vebleniana à ortodoxia de sua época, as ideias de Veblen tenham sido ignoradas pelos novos institucionalistas, que de certa forma pertenciam à ortodoxia neoclássica, ainda que se apresentem como críticos desta. Além de se distanciar da definição vebleniana de instituição, Commons parte da escassez de recursos como origem dos conflitos sociais, não de hábitos mentais distintos, como queria Veblen. Tanto a ideia de escassez de recursos quanto o conceito de transações e de instituições fizeram de Commons o único velho institucionalista reconhecido pela NEI de Coase, North e Williamson. Contudo, verificamos que, embora os autores referidos pertençam a escolas institucionalistas específicas, isso não garante uma unidade quanto ao conceito de instituição, nem no âmbito da VEI nem no da NEI.

Enquanto Veblen e Mitchell compartilham uma ideia de instituição como hábito mental, adquirido nas atividades cotidianas das pessoas, Commons possui uma com- preensão de instituição como regras balizadoras do comportamento humano, que caso seja deixado livre produzirá conflitos solucionados com base na força física. Já Coase e Williamson entendem instituição como regras internas às organizações - como as firmas, por exemplo - responsáveis pela alocação dos recursos escassos. Essa ideia de regra é distinta, e mais restrita, daquela sugerida por Commons e até por North, que vê as instituições como regras do jogo - formais e informais - de uma sociedade. North se aproxima da ideia vebleniana de hábito mental quando fala em ideologia, em seus escritos da década de 1990, aprofundando-se no tema em seus escritos da década de 2000, quando o autor fala explicitamente em hábitos mentais como as regras do jogo internalizadas pelo indivíduo.

Vimos que Hodgson busca uma conciliação entre a VEI e a NEI, principalmente entre o pensamento de Veblen e o pensamento de North. Contudo, distinções metodológicas importantes ainda distanciam uma completa conciliação entre o pensamento de North e Veblen ${ }^{8}$. Já Chang coloca-se como crítica da NEI, em que seu alvo principal é o pensamento de North. Segundo Chang, North teria focado excessivamente a ideia de instituição como regra restritiva, não reconhecendo seu papel de habilitadora e constituinte da ação individual.

Assim sendo, apesar de a VEI e a NEI serem comumente posicionadas em lados opostos, quando se destaca a compreensão de instituição dos autores dessas escolas institucionalistas, o que se observa são algumas interseções entre a VEI e a NEI, bem como algumas divergências internas quanto à perspectiva de análise no âmbito de cada uma dessas escolas. Por fim, essa confusão em torno do conceito de instituição poderia ser desfeita, ou ao menos começar a se apontar uma solução, caso fossem considerados alguns aspectos metodológicos envolvidos na relação entre estruturas sociais e sujeitos. Uma análise metodológica completa da economia institucional não faz parte do objetivo desse artigo, de modo que aqui somente podemos apontar um possível caminho para o encaminhamento da questão relativa à definição de instituição, permanecendo seu tratamento efetivo objeto para um artigo futuro.

\section{REFERÊNCIAS}

BACKHOUSE, R. A History of modern economic analysis. Oxford: Basil Blackwell, 1985.

BUENO, N. P. Lógica da ação coletiva, instituições e crescimento econômico: uma resenha temática sobre a nova economia institucional. Revista EconomiA, v. 5, n. 2, p. 361-420, jul// dez. 2004.

8 Ver, por exemplo, Cavalcante (2007) 
CAVALCANTE, C. M. Análise metodológica da economia institucional. Dissertação de Mestrado. Departamento de Economia, Universidade Federal Fluminense, Niterói, 2007.

CAVALCANTE, C. M. A Vitivinicultura no Vale do São Francisco: evolução institucional no sertão nordestino. Tese de Doutorado. Departamento de Economia, Universidade Federal Fluminense, Niterói, 2010.

CHANG, H. J. Breaking the mould: an institutionalist political economy alternative to neo-liberal theory of the market and the state. Cambridge Journal of Economics, v. 26, n. 5, p. 539559, set. 2002.

CHANG, H. J. Understanding the relationship between institutions and economic development - some key theoretical issues. In: Wider Jubilee Conference, Helsinki, 2005. (Mimeo)

CHANG, H. J.; EVANS, P. The role of institutions in Economic Change. In: DYMSKI, G.; PAUL, S. (Eds.) Re-imagining Growth. London: Zed Press, 2005, p. 99-140.

COASE, R. The nature of the firm. Economica, p. 386-495, nov. 1937. Disponível em: <http:// people.bu.edu/vaguirre/courses/bu332/nature_firm.pdf >. Acesso em: 1 ago. 2005.

COASE, R. The problem of social cost. Journal of Law and Economics, v. 3, n. 1, p. 1-44, 1960. Disponível em: <http://www.sfu.ca/ allen/CoaseJLE1960.pdf >. Acesso em 1 ago. 2005.

COASE, R. The firm, the market and the law. Chicago: University of Chicago Press, 1990

COASE, R. The new institutional economics. The American Economic Review, v. 88, n. 2, p.72-74, mai. 1998.

CONCEIÇÃO, O. A. C. Instituições, crescimento e mudança na ótica institucionalista. Teses FEE, Porto Alegre, n. 1, mar. 2002a.

CONCEIÇÃO, O. A. C. O conceito de instituição nas modernas abordagens institucionalistas. Revista de Economia Contemporânea, v. 6, n. 2, p. 119-146, jul./dez. 2002b.

COMMONS, J. Institutional economics. American Economic Review, v. 21, p. 648-657, 1931.

DEQUECH, D. Bounded rationality, institutions, and uncertainty. Journal of Economic Issues, v. 35, n. 4, p. 911-928, jun. 2001.

DEQUECH, D. The demarcation between the "old" and the "new" institutional economics: Recent Complications. Journal of Economic Issues, v. 34, n. 2, p. 565-572, jun. 2002.

FERRARI, F.; CONCEIÇÃO, O. A. C. A noção de incerteza nos pós-keynesianos e institucionalistas: uma conciliação possível? In: Encontro Nacional de Economia da ANPEC, 29, Salvador, 2001.

FURUBOTN, E.; RICHTER, R. Institutions and economic theory: the contribution of the new institutional economics. 2 ed. Ann Arbor: The University of Michigan Press, 2005.

HODGSON, G. The return of institutional economics. In: SMELSER, N.; SWEDBERG, R. (Eds.) The Handbook of Economic Sociology. New York: Princeton University Press, 1994, p. 58-76.

HODGSON, G. Evolution and Institutions: on evolutionary economics and the evolution of economics. Cheltenham: Edward Elgar, 1999.

HODGSON, G. What is the essence of institutional economics? Journal of Economic Issues, v. 34, n. 2, p. 317-329, jun. 2000 .
HODGSON, G. A evolução das instituições: uma agenda para pesquisa teórica futura. Revista Econômica, v. 3, n. 1, p. 97-125, jun. 2001

HODGSON, G. What are Institutions? Journal of Economic Issues, v. 40, n. 1, mar. 2006

HODGSON, G.; KNUDSEN, T. The complex evolution of a simple traffic convention: the functions and implications of habit. Journal of Economic Behavior \& Organization, v. 54, p. 19 47, 2004.

MEDEIROS, C. A. Instituições, Estado e mercado no processo do desenvolvimento econômico. Revista de Economia Política, v. 5, n. 1, p. 49-76, jan./jun. 2001.

MITCHELL, W. The rationality of economic activity: I. The Journal of Political Economy, v. 18, n. 2, p. 97-113, fev. 1910a.

MITCHELL, W. The rationality of economic activity: II. The Journal of Political Economy, v. 18, n. 3, p.197-216, mar. 1910b.

MITCHELL, W. Human behavior and economics: a survey of recent literature. The Quarterly Journal of Economies, v. 29, n. 1, p. 1-47, nov. 1914.

NORTH, D. Structure and change in economic history. New York: Norton, 1981.

NORTH, D. Institutions, institutional change and economic performance. Cambridge: Cambridge University Press, 1990

NORTH, D. Institutions. The Journal of Economic Perspectives (1986-1998), v. 5, n. 1, 1991.

NORTH, D. Institutions and economic theory. American Economist, v. 36, n. 1, 1992

NORTH, D. Understanding the process of economic change. Princeton: Princeton University Press, 2005.

RIZZELLO, S. "Bounded rationality". In: RIZZELLO, S. The Economics of the mind. Cheltenham: Edward Elgar, 1997.

RUTHERFORD, M. Thorstein Veblen and the process of institutional change. History of Political Economy, v. 16, n. 3, p. 331-348, 1984.

RUTHERFORD, M. Institutions in economics: the old and the new institutionalism. Historical perspectives on modern economics. Cambridge: Cambridge University Press, 1994.

RUTHERFORD, M. Veblen's evolutionary programme: a promise unfulfilled. Cambridge Journal of Economics, v. 22, p. 463-477, 1998.

RUTHERFORD, M. Institutional economics: then and now. Journal of Economic Perspectives, v. 15, n. 3, p.173-194, 2001.

SIMON, H. Bounded rationality, s. d. (Mimeo)

SIMON, H. "From substantive to procedural rationality". In: HAHN, F.; HOLLIS, M. (Eds.) Philosophy and economic theory. Oxford: Oxford University Press, 1979, p. 65-86.

THÉRET, B. As instituições entre as estruturas e as ações. Lua Nova, n. 58, p. 225-254, 2003.

VEBLEN, T. Why is Economics not an evolutionary science? In: VEBLEN, T. The place of science in modern civilization and other essays. New York: Russel \& Russel, 1961[1898], p. 56-81.

VEBLEN, T. The place of science in modern civilization and other essays. New York: Russel \& Russel, 1961. 
VEBLEN, T. A teoria da classe ociosa: um estudo econômico das instituições. São Paulo: Nova Cultural, 1988[1899].

WILLIAMSON, O. “Transaction cost economics". In: WILLIAMSON, O. The economic institution of capitalism. London: The Free Press, 1985, p. 15-42.

WILLIAMSON, O. Introduction. In: WILLIAMSON, O.; WINTER, S. (Eds.) The nature of the firm: origins, evolution, and development. Oxford: Oxford University Press, 1993a, p. 3-17.

WILLIAMSON, O. The logic of economic organization. In: WILLIAMSON, O.; WINTER, S. (Eds.) The nature of the firm: origins, evolution, and development. Oxford: Oxford University Press, 1993b, p. 90-116. 